\title{
Economic Analysis of Greenhouse Gas Mitigation Potential in the US Forest Sector
}

\author{
Justin S. Baker, Brent L. Sohngen, Sara Ohrel, and Allen A. Fawcett
}

The 2015 United Nations Framework Convention on Climate Change (UNFCCC) Conference of the Parties (COP) resulted in the Paris Agreement, a global climate accord of 176 Parties comprising individual countries and various coalitions. Collectively, the Parties proposed to address climate change through greenhouse gas (GHG) mitigation actions and use of adaptation measures in vulnerable regions and sectors. To reach a global agreement, the Parties submitted intended nationally determined contributions (INDCs), which communicated each Party's unique contributions to GHG emissions abatement and/or adaptation measures. In November 2016, the Paris Agreement entered into force (after triggering the threshold of at least 55 Parties to the Convention accounting for at least 55 percent of the total global GHGs emissions formally signed onto the Agreement), with 112 Parties of 197 Parties to the UNFCCC ratifying it, and submitting their final nationally determined contributions (NDCs).* Many INDCs and NDCs submitted emphasize mitigation action to reduce net emissions relative to some historic base or projected future period. Fifty percent of the 155 Parties that submitted GHG-targets expressed their GHG reduction targets relative to a business as usual (BAU) scenarios (mostly non-Annex 1 countries) and 39 percent included a base year emissions target (most commonly 1990,

\footnotetext{
* On June 1, 2017, the President of the United States announced that "the United States will withdraw from the Paris climate accord... But begin negotiations to re-enter either the Paris accord or really entirely new transaction....' The scenarios presented in this paper examine GHG mitigation potential in the US forest sector, and place that mitigation potential in context by comparing it to the range of mitigation that would have been required by the original US NDC submission. Although the original intent of this analysis was to inform policymakers' efforts to meet the US NDC goal, this analysis is equally informative for policymakers' efforts to meet any future mitigation target.
}

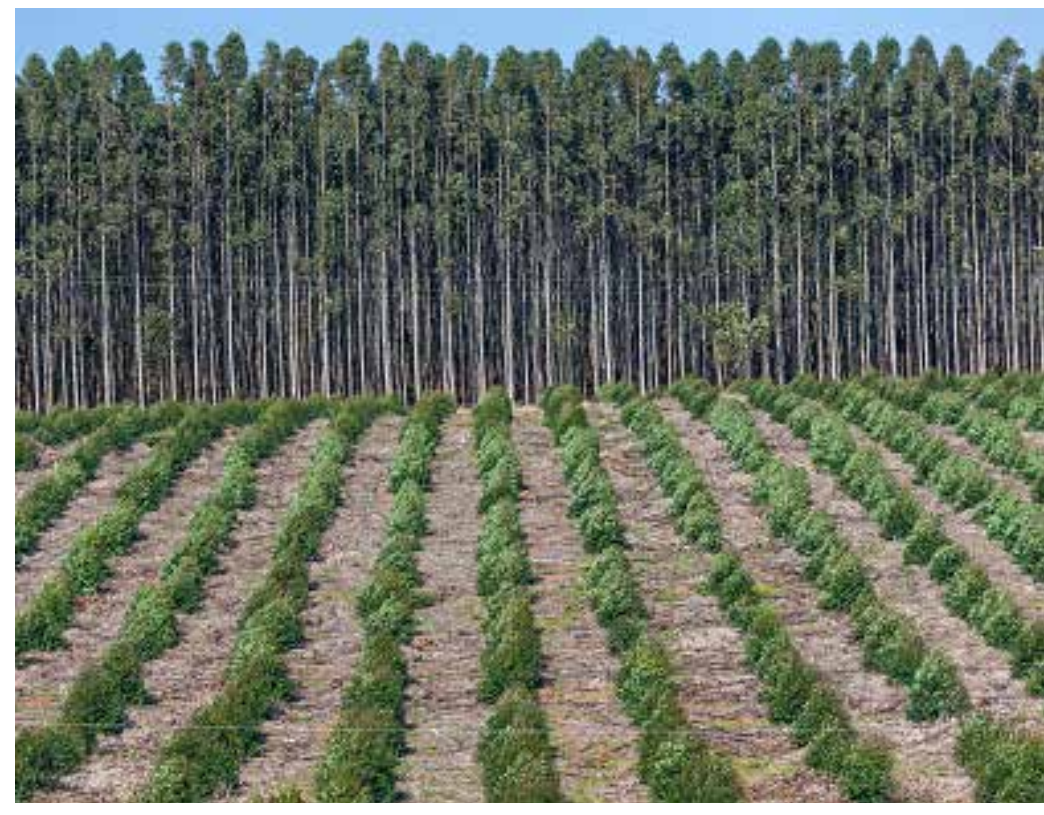

2005, and 2010). ${ }^{1}$ The US 2015 INDC included an ambitious near-term GHG emission goal of 26 to 28 percent emissions reductions relative to 2005 levels by 2025 . Achieving these previous commitments could require concerted mitigation effort in multiple sectors of the economy, including energy, transportation, industry, and land use (agriculture and forestry). Mitigation action could include renewable energy development in the energy sectors or increased carbon sequestration in the land use sectors.

Although the US 2015 INDC established a clear GHG emissions reduction target for 2025, the amount of additional mitigation that would be needed relative to the nation's business as usual (BAU) emissions levels at that point in time, 
under current policies, is unclear. The Second US Biennial Report offers future estimates for the nation's "Current Measures" BAU emissions projections, reflected by two potential outcomes: high sequestration and low sequestration. ${ }^{2}$ This range of future baseline estimates acknowledges that projected emissions, especially those from the land use sectors, are highly uncertain due to challenges associated with measuring complex ecological processes and biophysical attributes while anticipating future related commodity market demands.

Recent literature shows a wide range in future US forest sector emissions, with Wear and Coulston and Latta et al. indicating lower annual sequestration rates over time, ${ }^{3,4}$ while Tian et al. show a relatively stable US forest carbon sink (net sequestration level) that grows slightly in the near term. ${ }^{5}$ How US forest emissions change over time will have important implications for US commitments. Figure 1 shows the US 2025 mitigation range from the 2015 US INDC, along with the two potential current measures net emissions trajectories for the United States from the second biennial report reflecting the policies and measures that existed at the time of the report, and high and low assumptions for the US forestry and land use sink. The 2025 mitigation levels were calculated relative to 2005 for four separate scenarios (high and low sequestration, assuming 26 and 28 percent reduction for each).

Figure 1. GHG annual projections from the US 2016 Second Biennial Report to the UNFCCC (assuming 26 to 28 percent emissions reduction relative to 2005 )

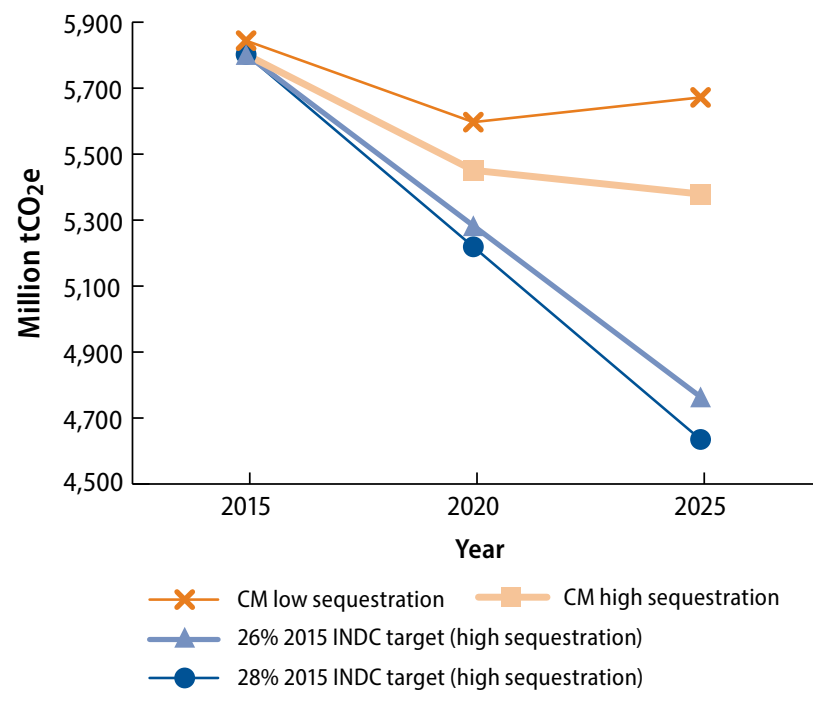

$\mathrm{CM}=$ additional measures; $\mathrm{GHG}$ = greenhouse gas;

$\mathrm{tCO}_{2} \mathrm{e}=$ metric tons of carbon dioxide equivalent; seq. = sequestration; UNFCCC = United Nations Framework Convention on Climate Change; percentage reductions are relative to a 2005 base period emissions level.
Since mitigation commitments are relative to a historic base period (2005) instead of a projected future period, moving forward on a high or low sequestration trajectory would result in less or more required mitigation for the United States to reach its 2015 commitment. Total additional mitigation required by 2025 to reach the 26 to 28 percent reduction goals ranges from 615 million metric tons of carbon dioxide equivalent $\left(\mathrm{MtCO}_{2} \mathrm{e}\right)$ to $1,037 \mathrm{MtCO}_{2}$ e per year (Figure 2).

Figure 2. Additional mitigation needed above the current measures high and low sequestration cases presented in the 2016 Biennial Report to achieve the 2015 US INDC target of 26 to 28 percent net emissions reductions compared to 2005 levels

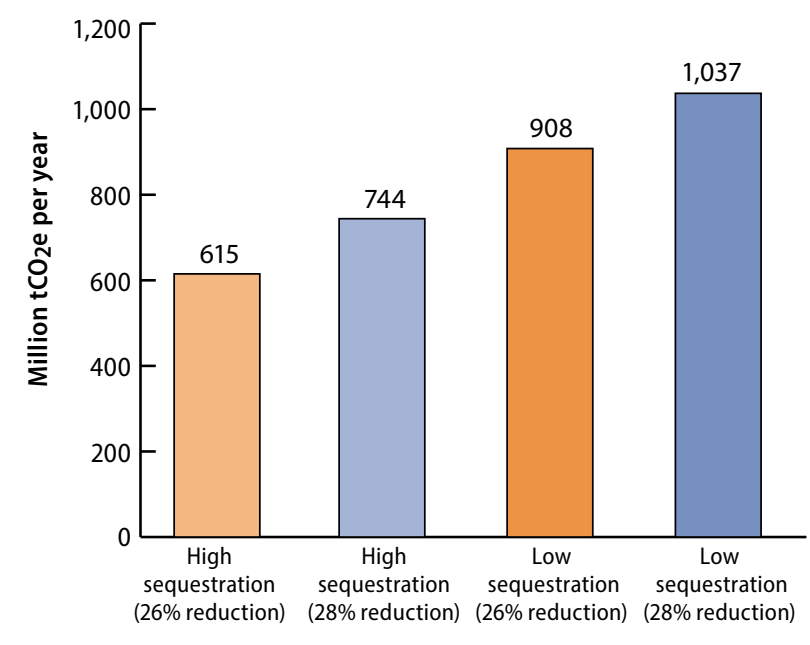

Additional mitigation required by 2025

Note: $\mathrm{tCO}_{2} \mathrm{e}=$ metric tons of carbon dioxide equivalent.

Source: US Department of State. 2016 second biennial report of the United States of America under the United Nations Framework Convention on Climate Change. 2016 [cited 2016 Sep 19]; Available from: https://unfccc.int/files/national_reports/biennial_ reports_and_iar/submitted_biennial_reports/application/pdf/2016_second_biennial_ report_of_the_united_states_.pdf

Given both the uncertainty in projected emissions from the land use sectors and the uncertainty in the effectiveness of the additional measures discussed in the 2016 Second Biennial Report, it is important to evaluate how policy mechanisms can incentivize additional carbon sequestration from US forests. Increased carbon sequestration in US forests could help close the gap between projected emissions and assumed mitigation requirements from the 2015 US INDC or any alternative future commitment. Also, if the United States finds itself following a higher than anticipated emissions trajectory, land-based mitigation incentives can help steer the nation back toward a "high sequestration" trend. This study uses a detailed economic model of the global forestry sector and a series of custom mitigation policy scenarios to project GHG abatement potential from the US forest sector. Results are evaluated relative to projected emissions from the 2016 Biennial Report $^{2}$ and previous mitigation levels from the 2015 US INDC. Our 
results indicate that with strong mitigation price incentives, the US forest sector can contribute 5 to 45 percent of the additional mitigation needed to meet the 2015 US INDC targets in 2025.

\section{Methods and Scenario Design}

This analysis applies a recently updated version of the Global Timber Model (GTM), following the analytical approach described in Sohngen and Sedjo ${ }^{6}$ and Daigneault and colleagues. ${ }^{7}$ GTM is an intertemporal optimization model of the global forest sector that can be used to evaluate forest management and forest product markets over time and under a wide range of policy scenarios. Intertemporal optimization is a modeling framework that is used to solve economic models over long time frames, and is particularly useful in a forest resource setting in which management, planting, and land use decisions are made with anticipation of future returns on the initial investment. Tian et al. provide an overview of this framework and the importance of intertemporal dynamics and other key attributes of GTM (e.g., endogenous forest management and representation of forest markets) for projecting GHG emissions. ${ }^{5}$ This study applies the modeling framework in Tian et al. to evaluate mitigation potential from the US forest sector under assumed GHG price incentives. We evaluate how strong mitigation price incentives can shift the nation's management profiles and land use to result in an increased carbon sink.

This optimization-based framework is well suited for mitigation analysis because it explicitly recognizes the opportunity costs (or trade-offs) of managing forest land for carbon relative to traditional management and harvest cycles for wood products. Dynamic optimization models of natural resource systems allocate natural resources efficiently over time and across competing uses. Resource management decisions directly influence market outcomes (e.g., prices and supply). Managing forests for increased carbon sequestration in this modeling framework directly influences market prices and, hence, resource management over time. With rising prices for primary forest products, market participants have greater incentive to produce more primary products. Thus, mitigation potential in this framework reflects opportunity costs of the resource-when more of the forest is set aside for GHG mitigation purposes, the market is directly impacted, which influences mitigation measures relative to what is found using other analytical frameworks (e.g., reduced form statistical simulation models) that do not account for these market feedbacks. A number of examples of statistical (econometric) simulation analyses provide more optimistic projections of mitigation potential, but fail to account for market feedbacks in a dynamic or systematic way, as considered in this analysis. 8,9
Additionally, GTM explicitly tracks forest carbon over time in existing and new forest stands. Carbon accumulation is tied to biomass yield curves that vary by management system, species, and region. Specifically, the model accounts for the following forest carbon pools: aboveground biomass (including deadwood, slash), belowground (e.g., roots, litter), and soil carbon. This dynamic carbon tracking allows for the projection of differences in mitigation potential over time. Thus, we can compare near-term GHG abatement for the time frame relevant to NDC implementation (2015-2030) to the long term when climate stabilization concerns grow (over 50 or more years). GTM does not represent carbon flux projections for urban forests, agricultural soils, or landfilled yard trimmings/ food scraps, so the analysis is not a comprehensive assessment of all land use, land use change, and forestry (LULUCF) emissions under mitigation prices. Therefore, for the purposes of this policy brief, we provide estimates of only the forest sector carbon pools within GTM (including carbon stored in hardwood products).

This analysis includes a baseline and 12 custom mitigation scenarios with different levels of assumed carbon prices. Demand is driven by macroeconomic forces, including gross domestic product, population, and forest biomass energy demand based on the Annual Energy Outlook 2015 Reference Case. ${ }^{10}$ The baseline reflects expected BAU levels of increased demand for wood products (including sawtimber, pulpwood, and biomass for energy). The baseline projections results show increased US sawtimber and pulpwood production over time, with fairly stable global prices throughout the simulation horizon. The model baseline is simulated over a 200 -year time frame to capture full growth and harvest cycles of different forest types.

To evaluate mitigation potential in the US forest sector, we introduce carbon price incentives into the model, a fairly common approach for evaluating mitigation potential in the land use sectors. ${ }^{11-14 \dagger}$

These incentives recognize the potential value of carbon remaining in forested stands and provide a direct payment to maintain or increase the volume of carbon stored in standing forests and wood products. The value of stored carbon competes with the demand for forest biomass for sawtimber, pulp and paper products, and bioenergy, which requires continuous harvest levels over time. Relative to a baseline with no assumed mitigation incentives, these carbon payments can shift land use and forest management profiles to increase total carbon storage. Consistent with most bottom-up and modeled

$\dagger$ For a detailed discussion of various economic modeling methods for evaluating mitigation policy incentives, refer to Van Winkle et al. ${ }^{15}$ 
mitigation analyses, total mitigation increases with the carbon price.

Price incentives were developed using a wide range of starting mitigation price values (ranging $\$ 10 / \mathrm{tCO}_{2} \mathrm{e}-\$ 50$ / $\mathrm{tCO}_{2} \mathrm{e}$ ) and growth rates to reflect increasing mitigation price incentives over time. Specifically, this study evaluates four total mitigation price scenarios, as summarized in Table 1. Two of these scenarios (starting at $\$ 10$ and $\$ 35$ per $\mathrm{tCO}_{2} \mathrm{e}$ ) assume a constant rate of growth in mitigation price incentives through the simulation horizon ( $2.5 \%$ and $2 \%$, respectively), while two additional scenarios with the same starting prices assume these growth rates until year 2120 in the simulation horizon, and then assume a constant mitigation price beyond this point. Two additional scenarios are included to reflect a more aggressive starting price ( $\$ 50$ at 1 percent growth) and extremely high prices in the long term ( $\$ 20$ at 5 percent growth, constant after 2120). The evolution of carbon prices over the long term is important in these simulations, as anticipated growth in mitigation incentives affects planting and management decisions in the near term to achieve higher carbon payments in the long term.

These mitigation scenarios are developed to reflect relatively high and low price incentives that rise over time at different rates. If forest sector mitigation action is incentivized through policy action involving price-based incentives targeted at private and public forest resource systems, some uncertainty exists with regard to the potential price that would be paid for emissions reduction and how this price might evolve over time. The sensitivity analysis represented here accounts for a broad range of potential prices and growth rates to show how near- and long-term mitigation potential varies with carbon price expectations.

Also, in the 2015 US INDC context, some uncertainty exists regarding how mitigation actions will be pursued in the LULUCF sectors, both domestically and abroad. Many

Table 1. Scenario names and mitigation price incentives

\begin{tabular}{|c|c|c|}
\hline $\begin{array}{l}\text { Scenario } \\
\text { name }\end{array}$ & $\begin{array}{l}\text { Starting price } \\
\left(\$ / \mathrm{tCO}_{2}\right)\end{array}$ & $\begin{array}{l}\text { Average annual } \\
\text { increase }\end{array}$ \\
\hline Baseline & $\mathrm{N} / \mathrm{A}$ & $\mathrm{N} / \mathrm{A}$ \\
\hline$\$ 10$ at $2.5 \%$ per year & $\$ 10$ & $2.5 \%$ per year \\
\hline $\begin{array}{l}\$ 10 \text { at } 2.5 \% \text { per year } \\
\text { (constant after } 2120 \text { ) }\end{array}$ & $\$ 10$ & $\begin{array}{l}2.5 \% \text { per year, constant after } \\
2120\end{array}$ \\
\hline$\$ 20$ at $5 \%$ per year & $\$ 20$ & $5 \%$ per year, constant after 2120 \\
\hline$\$ 35$ at $2 \%$ per year & $\$ 35$ & $2 \%$ per year \\
\hline $\begin{array}{l}\$ 35 \text { at } 2 \% \text { per year } \\
\text { (constant after } 2120 \text { ) }\end{array}$ & $\$ 35$ & $2 \%$ per year, constant after 2120 \\
\hline$\$ 50$ at $1 \%$ per year & $\$ 50$ & $1 \%$ per year \\
\hline
\end{tabular}

$\mathrm{N} / \mathrm{A}=$ not applicable; $\mathrm{tCO}_{2} \mathrm{e}=$ metric tons of carbon dioxide equivalent.
Parties are developing GHG mitigation plans that will involve unilateral policy action, while others are building strategies based on expectations of broader global action. To account for the possibility that the United States could pursue land-based mitigation action independently-without other countries also engaging in land- based actions, or in combination with all other countries also pursuing their "optimal" forest-based options-this analysis runs mitigation price scenarios under two policy frameworks:

- US-only policy, in which only mitigation in the United States is directly incentivized domestically through price mechanisms, and

- global policy, in which forest sector mitigation is incentivized in all regions of the model globally.

Mitigation prices are converted to annual carbon rental payments that are applied to various carbon pools. (For a discussion of this approach, see Sohngen and Mendelsohn. ${ }^{11}$ ) These rental rates reflect the value of storing carbon in terrestrial and wood product pools. Carbon rent is paid only for standing forest stock; however, storage of carbon in harvested wood products is incentivized by paying the carbon price for carbon stored at the time the timber is harvested. This method is efficiently equivalent with the carbon tax and subsidy scheme proposed by van Kooten and colleagues. 16

\section{Results and Policy Implications}

Figure 3 shows $\mathrm{CO}_{2}$ flux trajectories over the first 50 years of the simulation horizon (under baseline and global mitigation price scenarios). It is important to note that this figure represents net sequestration, so a negative value indicates that,

Figure 3. US forestry annual net $\mathrm{CO}_{2}$ sequestration over time under baseline and global mitigation scenarios.

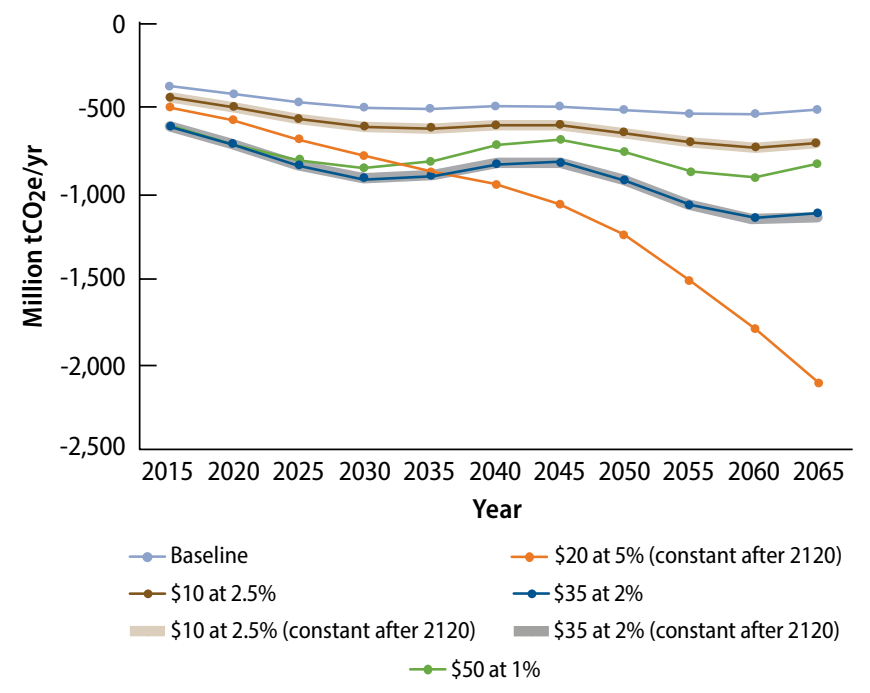


on an annual basis, the US forest sector is a net carbon sink, sequestering more carbon than is emitted through harvest activities. The baseline trajectory moves from relatively flat to slightly increasing over time, reflecting a fairly stable carbon flux in the United States. Tian et al. provide a more detailed discussion of these baseline results, ${ }^{5}$ but for purposes of this brief, we focus on comparing differences between the baseline and various mitigation scenarios. The difference in net sequestration between these policy-specific flux projections and the baseline flux reflects net mitigation potential.

Ultimately, the most basic interpretation of our results is that when forest-based mitigation is incentivized through price mechanisms, net terrestrial sequestration increases. The results from the different pricing scenarios, however, show a more complex story about timing, market participation, and mitigation potential. In the near term (2015-2030), mitigation rises with the $\mathrm{CO}_{2}$ price. The greatest near-term mitigation occurs under the highest initial price cases (the $\$ 35$ at

2 percent and $\$ 50$ at 1 percent scenarios), although the $\$ 20$ at 5 percent case shows substantial mitigation potential over the long term as prices rise rapidly. With this rapid price increase, the model favors mitigation action over time. Sequestration projections are very similar for the $\$ 10 / \mathrm{tCO}_{2} \mathrm{e}$ and $\$ 35 / \mathrm{tCO}_{2} \mathrm{e}$ scenarios with and without continued growth in the mitigation price incentive beyond 2120. However, sequestration trends begin to diverge over the long term between scenarios that allow mitigation price incentives to increase through the simulation horizon and those that cap mitigation price growth in 2120 . This result suggests that forest managers could wait to participate in forest offset programs if higher mitigation prices are expected in the long term. Conversely, early actors are more likely to participate in an offset market if expected future mitigation incentives are more pessimistic.

In the 2045 period, a slight inflection point appears where there is a decrease in mitigation across most scenarios. This inflection occurs because of changes in management and planting in the initial periods after the policy is implemented. Mitigation incentives lead to afforestation and conversion of unmanaged systems to intensively managed systems like planted pine in the Southeast. Because these are fast-growing rotations (20-30 years), after the initial boost in carbon sequestration due to increased planting, an increase in harvest emissions occurs from 2040-2050 as these stands are harvested and replanted. After this 2045 period, mitigation trajectories return to a path similar to those of 2015 and 2035. Finally, although Figure 3 displays flux projections from only the global mitigation scenarios, the shape of the flux projections is nearly identical for the US-only scenarios.
Table 2 provides a comparison of average annual net mitigation potential over different time frames for each mitigation policy price path evaluated under both the US-only and global action scenario. The table illustrates two important conclusions.

First, average mitigation potential expands over time for each price path scenario, generally reflecting higher carbon rental payments and the long-term nature of forest investments. For example, because forest resources are subject to relatively long growth cycles, mitigation actions taken in the near term (e.g., afforestation) might take a decade or more to provide meaningful additional carbon sequestration. For purposes of mitigation action to meet 2025 goals, projected near-term (2015-2030) mitigation potential is a more meaningful metric than long-term estimates (beyond 2030). For the range of prices included in this study (shown in Table 2 across different time frames), these near-term results show net projected net mitigation potential ranging $54-292 \mathrm{MtCO}_{2} \mathrm{e}$ per year under a global policy. Assuming an average price of $\$ 30.5 / \mathrm{tCO}_{2}$ across all mitigation scenarios over this period, total mitigation costs would range from $\$ 1.65$ billion to $\$ 8.9$ billion per year.

For US-focused scenarios, the estimated range of near-term mitigation potential is higher than in the global action scenario, ranging 73-292 MtCO2e. This result means that if the United States were to be the only country in the world to undertake forest-based sequestration, then the costs of sequestration in the United States are lower. The US sequestration costs are lower because in the US-only case, more US forests take part in carbon mitigation strategies (such

\begin{tabular}{|c|c|c|c|c|c|c|}
\hline Range of years & \multicolumn{2}{|c|}{ 2015-2030 } & \multicolumn{2}{|c|}{$2030-2045$} & \multicolumn{2}{|c|}{ 2045-2060 } \\
\hline $\begin{array}{l}\mathrm{CO}_{2} \text { price range } \\
\left(\$ / \mathrm{tCO}_{2} \mathrm{e}\right)\end{array}$ & \multicolumn{2}{|c|}{$\$ 12-\$ 53$} & \multicolumn{2}{|c|}{$\$ 17-\$ 57$} & \multicolumn{2}{|c|}{$\$ 24-\$ 118$} \\
\hline $\begin{array}{l}\text { Mitigation price } \\
\text { scenarios }\end{array}$ & $\begin{array}{c}\text { US } \\
\text { policy }\end{array}$ & $\begin{array}{l}\text { Global } \\
\text { policy }\end{array}$ & $\begin{array}{c}\text { US } \\
\text { policy }\end{array}$ & $\begin{array}{l}\text { Global } \\
\text { policy }\end{array}$ & $\begin{array}{c}\text { US } \\
\text { policy }\end{array}$ & $\begin{array}{l}\text { Global } \\
\text { policy }\end{array}$ \\
\hline$\$ 10$ at $2.5 \%$ & 73 & 54 & 105 & 78 & 135 & 87 \\
\hline $\begin{array}{l}\$ 10 \text { at } 2.5 \%, \\
\text { constant after } 2120\end{array}$ & 73 & 54 & 105 & 76 & 135 & 85 \\
\hline $\begin{array}{l}\$ 20 \text { at } 5 \%, \\
\text { constant after } 2120\end{array}$ & 161 & 133 & 368 & 272 & 761 & 496 \\
\hline$\$ 35$ at $2 \%$ & 292 & 213 & 373 & 251 & 421 & 248 \\
\hline $\begin{array}{l}\$ 35 \text { at } 2 \%, \\
\text { constant after } 2120\end{array}$ & 292 & 212 & 373 & 254 & 421 & 255 \\
\hline$\$ 50$ at $1 \%$ & 276 & 198 & 298 & 197 & 257 & 147 \\
\hline
\end{tabular}

$\mathrm{MtCO}_{2} \mathrm{e}=$ million metric tons of carbon dioxide equivalent.

The $\mathrm{CO}_{2}$ price range is calculated across scenarios and over time for the three time frames displayed. 
as avoided conversion or longer harvest rotations) and the remaining active forestland timber returns are higher (due to reduced domestic supply) and/or demand shifts abroad. These outcomes (reduced domestic supply or demand shifts abroad) reduce the opportunity costs of domestic carbon sequestration activities. Hence, over the near term, the US-only policy scenarios result in 21 to 39 percent more mitigation than the global scenarios. This difference expands to 53 to 75 percent in the longer term, from 2045 to 2060 . Mitigation is higher in the longer term under the US-only case because forest harvests and production shift to other regions while the United States focuses on additional carbon sequestration. It is important to note, however, that a number of other major timberproducing countries, including Canada, China, and Brazil, are currently implementing mitigation policies in the forest sector. Furthermore, several European Union countries have pledged large financial commitments to support reduced deforestation and increased carbon sequestration in the developing world. ${ }^{\ddagger}$

\$ See the UNFCCC COP 21 Information Hub for details on current financial commitments. ${ }^{17}$
Thus, it is unlikely that a US-centric mitigation policy scope will be realized. Nonetheless, this policy design offers insight into how projected mitigation outcomes can be influenced by taking a narrow (national) perspective of climate mitigation opportunities in a sector with a strong global market. Domestic GHG abatement estimates from modeling frameworks that do not capture global market feedback can overestimate net mitigation potential.

To evaluate the projected range in estimated mitigation potential presented in Table 2 in an appropriate policy context, Figure 4 compares the range of projected mitigation potential over the next 15 years (as seen in Table 2) to the additional mitigation needed to achieve 26 and 28 percent emissions reduction targets by 2025 . We evaluate the range in our projected mitigation potential across all 12 scenarios included in this analysis relative to four alternative futures: 26 and 28 percent emissions reduction from the US 2015 INDC relative to both the "low" and "high" sequestration Current Measures baseline projections presented in the 2016 Second Biennial Report. Figure 4 shows the proportion of this study's projected mitigation totals relative to the implied

Figure 4. Proportion of US forest sector's projected mitigation potential to additional US INDC's mitigation requirements in 2025
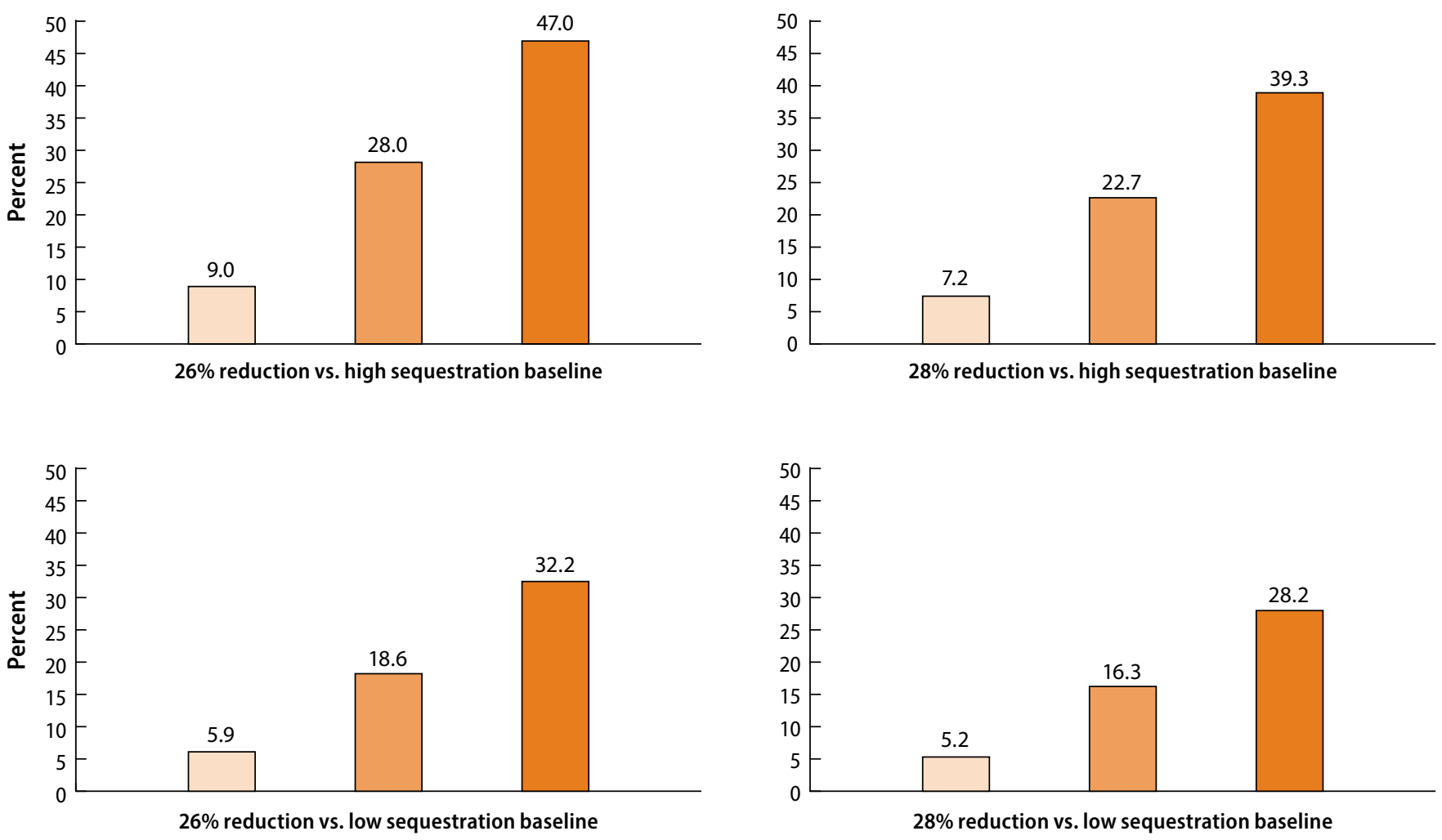

$\square$ Minimum mitigation

$\square$ Average mitigation

Maximum mitigation

Note: INDCs = intended nationally determined contributions 
additional emissions reduction needed under these four scenarios. The range resulting is depicted as the minimum, average, and maximum totals across all mitigation price paths and policy scenarios run for this analysis. Results show that US forest sector mitigation could account for approximately 5 to 47 percent of the additional mitigation needed to achieve US 2015 INDC emissions reduction targets across all four future scenarios. Under the "high" sequestration baseline projection, this relative proportion ranges 9 to 47 percent under an assumed 26 percent emissions reduction target and 7 to 39 percent under a 28 percent target. Under the "low" sequestration cases, where total emissions are higher, these relative proportions decrease to 6 to 32 percent and 5 to 28 percent for the 26 and 28 percent reduction targets, respectively.

Thus, even with a "low sequestration" baseline and the lowest assumed mitigation price incentives, results shows that US forestry can play a meaningful role in economy-wide emissions reduction, contributing more than 5 percent of the implied mitigation needed to reach 2015 US INDC targets, on average, across all scenarios and future baselines. Averaging across our abatement policies, this proportion exceeds 13 percent. These results also show that the US forest sector can play an increasingly important role in reducing emissions over the long term, especially if policies are implemented in the near term that adequately incentivize changes in land use and management that increase carbon uptake.

\section{Conclusions}

This study conducted an economic analysis of future US forest mitigation potential using a detailed economic model of the global forestry sector. The scenario design included a wide range of possible future carbon price incentives and climate policy structures (unilateral and global mitigation). Results across all scenarios show US forest sector mitigation potential ranging from 54 to $292 \mathrm{MtCO}_{2} \mathrm{e}$ between 2015 and 2030 (5 to 47 percent of the additional mitigation needed to achieve the 26 to 28 percent emissions reduction target).

This range is fairly low relative to other recent studies that have used statistical or econometric approaches to simulate GHG abatement under different prices, but those studies did not account for market feedbacks or connections to the global forestry system. Reduced form models that do not consider endogenous prices will underrepresent the opportunity costs of reduced or delayed timber harvests because there is no direct market feedback of reduced supply increasing market prices. Furthermore, estimates of mitigation potential from static (one-period) models can overstate annual mitigation potential relative to a dynamic framework that considers optimal long-term management of and investment in the resource base. However, even with lower mitigation totals, the results from this study suggest that the US forest sector can play an important role in GHG mitigation efforts, including efforts to meet any potential future US mitigation targets.

Achieving these abatement levels in the land use sectors will require concerted effort, which could include strong carbon price incentives that encourage land use and management changes that result in increased carbon uptake. Finally, decision makers should be cautious about relying on mitigation results from country-specific models and policy frameworks. The US-only policy scenarios presented here estimate higher levels of domestic mitigation potential than the global scenarios, but being that the Paris Agreement is a global accord, and there are a number of multilateral funding initiatives involving forest sector mitigation globally, modeling the effects of concurrent global action may yield more useful insights. Focusing on US-only policy within a global framework implicitly assumes that other countries are not pursuing similar mitigation actions (which is not consistent with INDCs and NDCs submitted under the Paris Agreement). If only country-level analyses are used to develop abatement contributions for a global agreement without accounting for global market dynamics, this could significantly overstate global net mitigation potential in the forestry sector. Taking into account international efforts to reduce emissions from the land use sectors and similar mitigation incentives in all regions, this study indicates that the net mitigation in the United States would be lower when compared with a US-only analysis.

\section{References}

1. Strohmaier R, Rioux J, Seggel A, et al. The agriculture sectors in the intended nationally determined contributions: analysis. Environment and Natural Resources Management Working Paper No.: 62. Rome, Italy: Food and Agriculture Organization of the United Nations; 2016.

2. US Department of State. 2016 second biennial report of the United States of America under the United Nations Framework Convention on Climate Change. 2016 [cited 2016 Sep 19]; Available from: https://unfccc.int/files/ national_reports/biennial_reports_and_iar/submitted_ biennial_reports/application/pdf/2016_second_biennial_ report_of_the_united_states_.pdf 
3. Wear DN, Coulston JW. From sink to source: Regional variation in US forest carbon futures. Scientific Reports. $2015 ; 5$.

4. Latta GS, Baker JS, Ohrel S, et al. Potential US forest greenhouse gas impacts of expanded EU wood pellet demand. Presentation given at 16th Symposium for Systems Analysis in Forest Resources, 2015; Uppsala, Sweden.

5. Tian X, Sohngen B, Baker JS, et al. Will US forests continue to be a carbon sink? Land Economics. In press.

6. Sohngen B, Sedjo R. Potential carbon flux from timber harvests and management in the context of a global timber market. Climatic Change. 2000;44(1-2):151-172.

7. Daigneault A, Sohngen B, Sedjo R. Economic approach to assess the forest carbon implications of biomass energy. Environmental Science \& Technology. 2012;46(11): 5664-5671.

8. Stavins RN. The costs of carbon sequestration: A revealedpreference approach. American Economic Review. 1999;89(4):994-1009.

9. Lubowski RN, Plantinga AJ, Stavins RN. Land-use change and carbon sinks: Econometric estimation of the carbon sequestration supply function. Journal of Environmental Economics and Management. 2006;51(2):135-152.

10. US Energy Information Administration. Annual Energy Outlook. 2015 [cited 2016 Sep 19]; Available from: http:// www.eia.gov/forecasts/aeo/

11. Sohngen B, Mendelsohn R. An optimal control model of forest carbon sequestration. American Journal of Agricultural Economics. 2003;85(2):448-457.

12. Murray BC, Sohngen BL, Sommer AJ, et al. Greenhouse gas mitigation potential in US forestry and agriculture (EPA-R-05-006). Washington, DC: US Environmental Protection Agency, Office of Atmospheric Programs; 2005. Available from: https://nepis.epa.gov/Exe/ZyPDF.cgi/ P100GO8M.PDF?Dockey=P100GO8M.PDF

13. Jackson RB, Baker JS. Opportunities and constraints for forest climate mitigation. Bioscience. 2010;60(9):698-707.
14. Adams DM, Alig RJ, McCarl BA, et al. Minimum cost strategies for sequestering carbon in forests. Land Economics. 1999;75(3):360-374.

15. Van Winkle C, Baker JS, Lapidus D, et al. US forest sector greenhouse mitigation potential and implications for nationally determined contributions. RTI Press Publication No. OP-0033-1705. Research Triangle Park, NC: RTI Press; 2017. Available from: https://doi.org/10.3768/rtipress.2017. op.0033.1705.

16. Vankooten GC, Binkley CS, Delcourt G. Effect of carbon taxes and subsidies on optimal forest rotation age and supply of carbon services. American Journal of Agricultural Economics. 1995;77(2):365-374.

17. United Nations Framework Convention on Climate Change. Paris COP21 information hub. 2016 [cited 2016 Sep 19]; Available from: http://newsroom.unfccc.int/ cop21parisinformationhub/

\section{About the Authors}

Justin S. Baker, PhD, RTI International

Brent L. Sohngen, PhD, The Ohio State University

Sara Ohrel, MEM, US Environmental Protection Agency

Allen A. Fawcett, PhD, US Environmental Protection Agency

\section{Acknowledgments}

This paper was supported by the US Environmental Protection Agency (EPA) (Contract EP-BPA-12-H-0023, Call Order \# EP-B15H-0143). The views and opinions expressed in this paper are those of the authors alone and do not necessarily state or reflect those of the EPA, and no official endorsement should be inferred.

RTI Press Research Briefs and Policy Briefs are scholarly essays on policy, methods, or other topics relevant to RTI areas of research or technical focus.

RTI International, 3040 East Cornwallis Road, PO Box 12194 Research Triangle Park, NC 27709-2194 USA

+1.919.541.6000ｒtipress@rti.org_www.rti.org

(O2017 RTI International. All rights reserved. Credit must be provided to the author and source of the publication when the content is quoted. No part of this publication may be reproduced in any form by any electronic or mechanical means without permission in writing from the publisher. RTI International is a registered trademark and a trade name of Research Triangle Institute.

RTI Press publication PB-0011-1708 www.rti.org/rtipress 